IZA DP No. 7348

Migration from Ukraine: Brawn or Brain?

New Survey Evidence

Simon Commander

Olexandr Nikolaychuk

Dmytro Vikhrov

April 2013

Forschungsinstitut

zur Zukunft der Arbeit

Institute for the Study

of Labor 


\title{
Migration from Ukraine: Brawn or Brain? New Survey Evidence
}

\author{
Simon Commander \\ Altura Partners, EBRD, \\ IE Business School and IZA
}

Olexandr Nikolaychuk

CERGE-EI

Dmytro Vikhrov

CERGE-EI

Discussion Paper No. 7348

April 2013

IZA

P.O. Box 7240

53072 Bonn

Germany

Phone: +49-228-3894-0

Fax: +49-228-3894-180

E-mail: iza@iza.org

Any opinions expressed here are those of the author(s) and not those of IZA. Research published in this series may include views on policy, but the institute itself takes no institutional policy positions. The IZA research network is committed to the IZA Guiding Principles of Research Integrity.

The Institute for the Study of Labor (IZA) in Bonn is a local and virtual international research center and a place of communication between science, politics and business. IZA is an independent nonprofit organization supported by Deutsche Post Foundation. The center is associated with the University of Bonn and offers a stimulating research environment through its international network, workshops and conferences, data service, project support, research visits and doctoral program. IZA engages in (i) original and internationally competitive research in all fields of labor economics, (ii) development of policy concepts, and (iii) dissemination of research results and concepts to the interested public.

IZA Discussion Papers often represent preliminary work and are circulated to encourage discussion. Citation of such a paper should account for its provisional character. A revised version may be available directly from the author. 
IZA Discussion Paper No. 7348

April 2013

\section{ABSTRACT}

\section{Migration from Ukraine: Brawn or Brain? New Survey Evidence ${ }^{1}$}

We study selection and labour market outcomes among Ukrainian migrants using unique data from a survey conducted in Ukraine in August - October 2011. We find that migrants are positively selected in terms of age and education. Yet, this is not associated, as might be expected, with their labour market outcomes. Notably, around half of the migrants are employed in occupations for which they are over-qualified. We conjecture that this downshifting in occupation can partly be explained by the absence of the conventional link between education and skills in Ukraine. To circumvent this problem, we compare pre- and post-migration labour market outcomes and find that the probability of downshifting decreases with the duration of stay in a foreign country and knowledge of the local language or English. Significantly, someone who downshifted prior to migration in the home country was more likely to downshift abroad. Further, we find that migrants to the EU are more likely to downshift when compared to other destinations.

JEL Classification: F22, J24

Keywords: migration, selection, occupation downshift, survey data

Corresponding author:

Simon Commander

EBRD

One Exchange Square

London EC2A 2JN

United Kingdom

E-mail:commanders@ebrd.com

\footnotetext{
${ }^{1}$ The research was generously supported by EBRD.
} 


\section{Introduction}

In recent decades, Ukraine saw a significant increase in cross-border migration, as well as a diversification in the direction of that migration away from other former Soviet states. This paper looks at the properties of cross-border Ukrainian migration, particularly in terms of the attributes of migrants. It is based on unique survey data that we collected in the second half of 2011. The main aim of the research is to understand more about the characteristics of migrants, so the survey was designed to permit testing for self-selection on some key observable characteristics. It was also designed to track details of employment history both prior to and after migration, a feature that distinguishes out data from the existing studies. We are also able to address directly the issue of whether migration from Ukraine constitutes a brain drain or gain. Respondents were classified into several migrant categories which allows us to make comparisons that are absent in much of the literature due to lack of data. In particular, we are able to observe the status of individuals once they migrate. Our survey allows for a fuller picture of the migrants'characteristics as sampling of the source population is known from the census.

Earlier research has found that the bulk of Ukrainian migrants were relatively low skilled but not much has been known about the type of employment outcomes associated with migration. Our data show that migrants tend to be positively self-selected on age and education. However, their occupational choice while abroad did not mostly correspond with observable education levels. Under the assumption that skills and education are tightly correlated, this suggests that migrants tend to downshift when finding work abroad. Part of this may be motivated by the fact that there are large income gaps between better paid and more skilled occupations in Ukraine and low paid occupations abroad. The gap is in favour of the latter. This implies that there might still be incentives for an individual with relatively low migration costs to downshift or choose an occupation that is seemingly a bad match for their educational background.

We find that nearly half of the migrants in our survey data are employed in occupations for which they are clearly overqualified. This is, of course, a feature found in some other studies of migrants' occupational choices ${ }^{2}$. The phenomenon of occupation downshifting, also referred to in the literature sometimes as "brain waste", persists across all education categories irrespective of the destination country. In the paper, we look at the nature and determinants of downshifting and link it to the issues of migrant self - selection as well as pre-migration employment. We look at two sets of factors in particular that may help account for downshifting. The first is the quality (or degree of transferability) of human capital acquired in Ukraine. The second concerns the search costs associated with looking for an occupation abroad. These costs could be expected to be related to factors such as knowledge of the local language, or English, as well as the duration of a migrant's stay in a given country or pre-migration work experience.

\section{Literature Review}

Our study bears relevance to several strands in the migration literature. It is primarily linked to the body of research on self-selection that investigates how the characteristics of migrants differ from non-migrants as well as the local population. ${ }^{3}$ These characteristics define how migrants

\footnotetext{
2 See, for example, Mattoo et al., 2008 and Kostenko et al., 2012.

${ }^{3}$ See Borjas,1987,Chiquiarand Hanson,2005and Moraga, 2011 amongst others
} 
affect receiving and sending economies, which links our study to the literature on the labour market performance of migrants as well as the brain drain / brain gain literature ${ }^{4}$.

Borjas (1987) first applied the self-selection framework to study the quality of migrants in the US. He defined three types of selection: positive selection (migrants are above average in income distribution, and thus in unobservable skills or ability, in both sending and receiving countries), selection of refugees (migrants are above average only in the receiving country) and negative selection (migrants are below average in both countries). Using data from the 1970 and 1980 population censuses, he found evidence for positive selection and increase in earnings over time for migrants from Western Europe, and negative selection and a decrease in earnings over time for those from less developed countries. Further empirical evidence on selection has been mixed. In the context of Mexico-US migration flows, Chiquiar and Hanson (2005), McKenzie and Rapoport (2010) find that the probability of emigration increases for those in the middle and high sections of the education distribution (positive selection). Moraga (2011), using longitudinal data, finds negative selection of migrants and shows that the distribution of the would-be-migrants' earnings drops in the pre-migration quarter. Elsewhere, Rooth and Saarela (2007) find that Finnish migrants to Sweden during 1989-1990 had on average 1 year of schooling less than non-migrants, consistent with the fact that for a decade prior to the period considered, Sweden had a smaller return to observable skills than Finland.

In part due to data availability, the majority of studies research the self-selection phenomenon from the point of view of the receiving country. This approach has its own problem. These can include lack of representativeness of the migrant population and of under-representation of certain categories of migrants (including illegal). For example, Hanson (2006) estimates that the undercounting of the illegal migrants in the stock data in the US Census to be of the order of $10 \%-25 \%$, while Moraga (2011) finds his negative selection results to differ from the positive selection of Chiquiar and Hanson (2005) only due to the undercounting of the lowskilled migrants in the data used by the latter.

Literature on the labour market performance of migrants can be subdivided into two strands: earnings assimilation and occupational attainments (Mattoo et al., 2008 for the US, Kostenko et al., 2012 for Australia, Turner, 2010 for Ireland). Mattoo et al. (2008) find that in the US labour market, migrants from Latin America and Eastern Europe are more likely to end up with lowskilled jobs than migrants from Asia and developed countries with similar characteristics. According to them, this variation is explained by low or poorly transferable skills obtained in certain source countries, as well as by selective US immigration policy. Poor quality or transferability of skills is also related to expenditures on tertiary education and use of English as a medium of instruction in the source countries. US immigration policy matters as migrants from certain countries are admitted through family reunification and visa lotteries whereas migrants from other countries have to make their way through the labour market.

The bulk of existing research (for example, Adsera and Chiswick, 2007 for migrants in the EU, Berman et al., 2003 for migrants in Israel) suggests that upon arrival migrants face a significant wage gap compared to locals in the same occupation with similar observables. However, it appears that migrants' wages grow faster and eventually converge to those of natives, although with some exceptions. Adsera and Chiswick (2007) find the gap to be on average $40 \%$ for all migrants but the gap widens for those born outside of the EU and varies across destination

\footnotetext{
${ }^{4}$ See for example Gibson and McKenzie (2012).
} 
countries. Berman et al. (2003) find that wages for migrants from the former Soviet Union in Israel converge to those in the upper part of the occupation distribution but the rate of convergence is closely linked to knowledge of Hebrew. They report no convergence in wages, irrespective of Hebrew proficiency, for occupations at the bottom of the distribution.

Self-selection has implications for sending and receiving economies. For the sending countries, the literature on brain drain argues that the dominant channel is through depriving the sending or developing country of skills required locally, thereby subtracting from the sending country's growth potential ${ }^{5}$. On the contrary, the brain gain literature suggests that with a positive migration probability, individuals will tend to obtain more human capital. Since only a small fraction actually emigrates, the sending country has a higher supply of human capital (see for example Commander et al., 2003, Batista et al., 2012). Gibson and McKenzie (2012) add to the discussion by suggesting that the probability of migration principally affects the choice of field of education, rather than the level. For the receiving economy, self-selection primarily affects migrants' labour market performance in terms of wages and occupational choice.

In the light of the above overview of the literature, we study self-selection of Ukrainian migrants from the perspective of the sending country. Quite recently, there have been two other large-scale migration surveys conducted in Ukraine: ETF (2008) and Libanova (2009). Both of these surveys, though to a varying extent, suffer from under-classification of the migrant categories and deficiencies in survey design as far as extracting relevant information about migrants is concerned. Compared to these surveys, our study has several advantages. First, we explicitly model migrant categories to allow for testing self-selection effects. Second, we collect information on the pre- and post-migration employment history of respondents and use it to explain the choice of current occupation. Our study contributes to the literature on the occupational distribution of migrants, linking the phenomenon of occupation downshifting with self-selection of migrants and their pre-migration employment details. Third, we directly ask respondents about any human capital accumulation in order to test the brain gain hypothesis directly.

\section{Survey Design}

The current study is based on a tailor-made survey. The population of interest was defined as persons in the labour force, males and females, aged 15-59, residing in non-institutionalised dwellings in settlements with a population size of 50,000 people and more. The decision to ignore the rural population was dictated by several considerations, including difficulties in achieving adequate coverage as well as the fact that Ukrainian domestic migration from rural to urban areas has historically been significant. As a consequence, earlier evidence suggests that the bulk of potential external migrants are resident in urban areas ${ }^{6}$.

Due to the differences in cultural and historical backgrounds across various geographical parts of Ukraine, as well as infrastructural diversities across settlements of various sizes, we stratified our sample by region and town size. Four geographical regions (West, Center and North, East, and South) and four town sizes (50-100K, 100-200K, 200-500K, 500K - 1mln residents)

\footnotetext{
${ }^{5}$ Bhagwati and Hamada (1974)

${ }^{6}$ There is one obvious exception. In the western part of Ukraine, much of the external migration to neighbouring countries has been from rural areas.
} 
resulted in a 4-by-4 stratification map. Large cities ( $>1 \mathrm{mln}$ residents) were further included as a separate stratum. The final individual observation weights on gender and 10-year age brackets were calculated using the relevant information from the Ukrainian State Statistical Office.

The data were collected by means of direct interviews with households in accordance with specific search routes that maximized the distance between each pair of sampling points in towns that had been randomly chosen within a particular stratification cell. Depending on availability within a selected household, responses were collected from one randomly chosen member without any (external) migration experience and from all members with such experience. To be considered a person with migration experience, a person had to fulfill one of the following criteria at the time of conducting the interview:

- be residing, working or studying abroad;

- having been abroad for the purpose of residence, employment or education in the last three years;

- be planning to leave abroad for the purpose of residence, employment or education in the next 12 months.

When it was not possible to gather information about a person directly we had to rely on other household members to respond.

The data were collected between August and October 2011. Altogether, we obtained information on 6676 individuals from 5985 households living in 63 towns of Ukraine.

\section{Descriptive Statistics}

Table 1 provides some basic descriptive statistics concerning the sample. It can be seen that the unweighted (weighted given in brackets) distribution of migrants across the categories was as follows. Those currently abroad were 409 (369), returnees numbered 216 (266) and prospective migrants were 320 (320) while non-migrants were 5739 (5720). In the discussion below, we weight the observations to generalize our results for the whole urban population. We further classify respondents from categories currently abroad and returnees as migrants.

Table 1 shows that, on average, a migrant is more likely to be a married man, aged below 40, and come from the middle or upper part of the education distribution.

Table 1: Basic descriptive statistics

\begin{tabular}{|c|c|c|c|c|c|c|c|c|}
\hline \multirow{2}{*}{ Variable } & \multicolumn{2}{|c|}{ Currently Abroad } & \multicolumn{2}{|c|}{ Returnees } & \multicolumn{2}{|c|}{ Prospective } & \multicolumn{2}{|c|}{ Non-Migrants } \\
\hline & $\mathrm{N}$ & $\%$ & $\mathrm{~N}$ & $\%$ & $\mathrm{~N}$ & $\%$ & $\mathrm{~N}$ & $\%$ \\
\hline Male & 245 & 66.4 & 196 & 73.7 & 199 & 62.2 & 2534 & 44.3 \\
\hline Age: & & & & & & & & \\
\hline Mean & 36.8 & & 37.3 & & 31.0 & & 37.5 & \\
\hline s.d. & 11.4 & & 10.3 & & 11.7 & & 12.8 & \\
\hline $15-19$ & 9 & 2.4 & 4 & 1.5 & 56 & 17.5 & 536 & 9.4 \\
\hline $20-29$ & 121 & 32.8 & 76 & 28.6 & 121 & 37.8 & 1342 & 23.5 \\
\hline $30-39$ & 82 & 22.2 & 66 & 24.8 & 56 & 17.5 & 1229 & 21.5 \\
\hline $40-49$ & 90 & 24.4 & 85 & 32.0 & 58 & 18.1 & 1286 & 22.5 \\
\hline $50-59$ & 67 & 18.2 & 35 & 13.2 & 28 & 8.8 & 1328 & 23.2 \\
\hline Marital stat & & & & & & & & \\
\hline Single & 97 & 26.3 & 46 & 17.3 & 151 & 47.2 & 1435 & 25.1 \\
\hline Married & 235 & 63.7 & 173 & 65.0 & 124 & 38.8 & 3270 & 57.2 \\
\hline cohabitation & 14 & 3.8 & 14 & 5.3 & 14 & 4.4 & 248 & 4.3 \\
\hline
\end{tabular}




\begin{tabular}{|c|c|c|c|c|c|c|c|c|}
\hline Divorced & 20 & 5.4 & 29 & 10.9 & 27 & 8.4 & 563 & 9.8 \\
\hline Widowed & 3 & 0.8 & 4 & 1.5 & 4 & 1.3 & 204 & 3.6 \\
\hline \multicolumn{9}{|l|}{ Education: } \\
\hline Primary & 0 & 0.0 & 0 & 0.0 & 0 & 0.0 & 12 & 0.2 \\
\hline basic secondary & 4 & 1.1 & 1 & 0.4 & 11 & 3.4 & 230 & 4.0 \\
\hline Complete secondary & 33 & 8.9 & 16 & 6.0 & 50 & 15.6 & 790 & 13.8 \\
\hline vocational & 82 & 22.2 & 114 & 42.9 & 60 & 18.8 & 1435 & 25.1 \\
\hline basic higher & 86 & 23.3 & 65 & 24.4 & 79 & 24.7 & 1441 & 25.2 \\
\hline Complete higher & 158 & 42.8 & 67 & 25.2 & 119 & 37.2 & 1786 & 31.2 \\
\hline candidate of & 5 & 1.4 & 3 & 1.1 & 1 & 0.3 & 25 & 0.4 \\
\hline doctor of sciences & 1 & 0.3 & 0 & 0.0 & 0 & 0 & 1 & 0.0 \\
\hline Total weighted & 369 & & 266 & & 320 & & 5720 & \\
\hline
\end{tabular}

We identify five categories for analysis of selection. They are: (1) those currently abroad as opposed to non-migrants; (2) returnees as opposed to non-migrants; (3) returnees as opposed to those currently abroad; (4) prospective as opposed to non-migrants; and (5) prospective as opposed to those currently abroad.

The currently abroad tend to be younger than non-migrants. More than $40 \%$ of the currently abroad have completed higher education (Master's degree or equivalent) compared to 31\% amongst the non-migrants. There is evidence of positive self-selection in terms of age and education. The returnees are likely to be married males coming from the middle part of the education distribution. Based on the education criterion alone there seems to be some selection on the part of the returnees as compared to the currently abroad and non-migrants. The prospective migrants tend to be particularly young and are largely dominated by single males. A significant share have completed higher education (>37\%).

The survey data yield a total migration rate of $10 \%$. However, there is large variation across administrative regions (see Table 1A and Figure 1A in Appendix). In general, there has been a small amount of migration from the central regions with relatively high migration rates in the Western parts, notably Odesa and Lugansk regions. In terms of the destination countries, the picture is also quite diverse, as can be seen in Table 2 .

Table 2: Destination Countries

\begin{tabular}{l|rr|rr|}
\multirow{2}{*}{ Destination } & Currently Abroad & \multicolumn{2}{|c|}{ Returnees } \\
& $\mathrm{N}$ & \multicolumn{1}{c}{$\%$} & $\mathrm{~N}$ & \multicolumn{1}{c}{$\%$} \\
\hline Russia & 144 & 39.0 & 134 & 50.2 \\
Italy & 36 & 9.8 & 20 & 7.6 \\
Poland & 25 & 6.9 & 31 & 11.7 \\
Germany & 23 & 6.2 & 15 & 5.8 \\
USA & 20 & 5.3 & 5 & 1.9 \\
Israel & 15 & 4.0 & 1 & 0.3 \\
Spain & 12 & 3.3 & 7 & 2.7 \\
Czech Republic & 9 & 2.4 & 12 & 4.5 \\
Greece & 7 & 1.8 & 8 & 2.9 \\
Portugal & 7 & 1.8 & 2 & 0.6 \\
UAE & 5 & 1.5 & 1 & 0.5 \\
UK & 5 & 1.3 & 3 & 1.1 \\
Other & 62 & 17.0 & 27 & 10.1 \\
\hline Total & $\mathbf{3 6 9}$ & & $\mathbf{2 6 6}$ &
\end{tabular}


There is a clear trend for respondents from the Western regions of Ukraine to go to the EU27 countries and for those from the Eastern part to go mainly to former Soviet Republics, primarily Russia. Indeed, the most frequently chosen destination was Russia $-40.1 \%$ and $50.2 \%$ of the currently abroad and return migrants respectively. Amongst the EU destinations Italy, Poland and Germany were the three most frequent while the USA, Israel and UAE were the three most favoured destinations in the rest of the world category. Even though this paper does not directly address the question of the choice of destination, we do find a non-linear effect between the size of the origin city in Ukraine and the probability to migrate, as well as different labour market outcomes for migrants across the destination country groups.

The existing research unambiguously suggests that the primary reason for migration is the difference in wage rates net of the total migration costs. In our survey nearly $77 \%$ of all migrants indicated that "better pay" and "better employment opportunities" as their primary reasons for migration. Table 3 summarizes data on self-reported average monthly incomes ${ }^{7}$. For an average non-migrant working in the manual labour sector in Ukraine, the reported income was US\$ 555. A migrant working in the manual labour sector abroad could earn on average at least twice as much. The reported income ranged from US\$ 1295 in the EU15 to US\$ 2043 in the EU10. The income gap persists and increases further up the occupation ladder. Further, the highest income sector in Ukraine has an average income level lower than the least rewarding one abroad. This implies that for a skilled Ukrainian with relatively low migration costs it may be attractive to take up an unskilled job abroad, thus avoiding the occupation search and integration costs. The data also suggest that return migrants do not necessarily get a "migration premium" for their experience abroad, a phenomenon also found by other authors (see, for example, Co et al., 2000 for returning Hungarians and Ambrosini and Peri, 2012 for returning Mexican migrants).

Table 3: Self-reported average income for 6 months prior to survey date (PPP US\$)

\begin{tabular}{l|ccccr} 
Sector & EU15 & EU10 & Russia & ROW & Ukraine \\
\hline Manual & 1294.8 & 2042.6 & 1717.8 & 1871.4 & 554.9 \\
Specialized manual & 1231.6 & 1689.9 & 1796.4 & 2048.2 & 672.4 \\
High-skilled & 1830.1 & 1563.3 & 2092.4 & 2097.5 & 737.9 \\
Narrow high-skilled & 4538.6 & 2551.0 & 1489.1 & 3314.1 & 876.8 \\
Administrative & 1924.1 & 2506.1 & 2701.1 & 2677.6 & 1158.0
\end{tabular}

As regards the reasons for returning home, 55\% of return migrants chose "personal reasons" and 31\% report "employment contract expiration, end of education etc". It thus seems that the decision to return is not entirely at the migrant's discretion, a fact that potentially reduces the selection bias if we consider returnees as opposed to those currently abroad. Around $40 \%$ of the migrants send remittances home, the rate being a bit higher for those currently abroad than for the returnees (45\% and 40\% respectively). The average weighted amount remitted is US\$ 535 for the currently abroad and US\$ 760 for the returnees ${ }^{8}$.

\footnotetext{
${ }^{7}$ Note that for the income question, we obtained high response rates; $58 \%$ for the currently abroad; $77 \%$ for the returness, $76 \%$ for the prospective migrants and $87 \%$ for the non-migrants.

${ }^{8}$ The remittances were predominantly in cash.
} 
The survey also asked respondents whether they had taken additional education or training in an attempt to improve their chances of migrating. Respondents' answers are summarized in Table $4^{9}$. The evidence in support of the brain gain hypothesis is weak.

Table 4: Responses to "Have you tried to improve your chances to migrate by any of the following?”

\begin{tabular}{l|rr|rr|rr|rr|} 
& \multicolumn{2}{|c|}{ Currently Abroad } & \multicolumn{2}{|c|}{ Returnees } & \multicolumn{2}{|c|}{ Prospective } & \multicolumn{2}{|c|}{ Non-Migrants } \\
& $\mathrm{N}$ & \multicolumn{1}{|c|}{$\%$} & $\mathrm{~N}$ & \multicolumn{1}{c|}{$\%$} & $\mathrm{~N}$ & \multicolumn{1}{c|}{$\%$} & $\mathrm{~N}$ & $\%$ \\
\hline Additional years of schooling & 11 & 3.0 & 0 & 0.0 & 7 & 2.2 & 16 & 1.6 \\
\hline Language classes & 59 & 16.0 & 14 & 5.3 & 61 & 19.1 & 115 & 11.3 \\
\hline Professional skills building & 55 & 15.0 & 20 & 7.5 & 33 & 10.3 & 48 & 4.7 \\
\hline Private classes & 14 & 3.8 & 0 & 0.0 & 4 & 1.3 & 16 & 1.6 \\
\hline Preparation for SAT & 16 & 4.3 & 6 & 2.3 & 7 & 2.2 & 10 & 1.0 \\
\hline Have not tried & 200 & 54.2 & 216 & 81.2 & 176 & 55.0 & 730 & 71.9 \\
\hline Other & 3 & 0.8 & 0 & 0.0 & 9 & 2.8 & 26 & 2.6 \\
\hline Do not know & 49 & 13.3 & 10 & 3.8 & 23 & 7.2 & 54 & 5.3 \\
\hline Respondents in category & $\mathbf{3 6 9}$ & & $\mathbf{2 6 6}$ & & $\mathbf{3 2 0}$ & & $\mathbf{1 0 1 5}$
\end{tabular}

As might be expected, prospective migrants are more active in obtaining additional skills than non-migrants. In particular, $19 \%$ of the prospective migrants took language classes, $10 \%$ had professional skill building and $2 \%$ took additional years of schooling. This compares to $11.3 \%$, $4.7 \%$ and $1.6 \%$ respectively amongst the non-migrants. There is little evidence of additional years of schooling.

\section{Labour Market Outcomes and Occupational Choice}

Looking at the labour market performance of migrants in their destination countries, a striking feature is that Ukrainian migrants abroad commonly downshift and take up work for which they are seemingly overqualified. A standard definition of a downshifter relates educational attainments at home to labour market matches abroad (Mattoo et al., 2008). The former is considered to reflect a person's unobservable skills while also setting an aspiration level. To gauge the nature of the match, our survey questionnaire not only collected information on educational attainments but also contained a five-point ranking of skills by which respondents ranked their current occupation. These categories were manual labour, specialized manual labour, general high-skill, specialized high-skilled and administrative. These two pieces of information allow contrasting education with occupation. A downshifter was defined as someone for whom one of following holds:

- Involuntarily unemployed;

- Employed in manual labour if the skill level is medium or high;

- Employed in specialized manual or manual labor if the skill level is higher.

Table 5 gives the occupational distribution of respondents controlling for their educational attainment. For the latter, the broad categories were applied; low skilled people defined as having primary and/or basic secondary education; medium skilled people with complete

\footnotetext{
${ }^{9}$ In the non-migrant category, the question was asked to those who had considered migrating which is why the number of answers drops to 1015.
} 
secondary and vocational education, high skilled individuals with tertiary education. Migrants classified as downshifters are shaded grey in Table 5. It appears that $43 \%$ of medium-skilled and $56 \%$ of high-skilled respondents had to downshift whilst working abroad. In total 288 individuals or just over $44 \%$ of migrants downshifted.

Table 5: Occupational distribution of respondents ${ }^{10}$

\begin{tabular}{|c|c|c|c|c|c|c|c|c|c|}
\hline & \multicolumn{3}{|c|}{ Low-Skilled } & \multicolumn{3}{|c|}{ Medium-Skilled } & \multicolumn{3}{|c|}{ High-Skilled } \\
\hline & \multicolumn{2}{|c|}{ Migrants } & \multirow{2}{*}{$\begin{array}{c}\text { Non- } \\
\text { Migrants }\end{array}$} & \multicolumn{2}{|c|}{ Migrants } & \multirow{2}{*}{$\begin{array}{c}\text { Non- } \\
\text { Migrants }\end{array}$} & \multicolumn{2}{|c|}{ Migrants } & \multirow{2}{*}{$\begin{array}{l}\text { Non- } \\
\text { Migrants }\end{array}$} \\
\hline & Before & After & & Before & After & & Before & After & \\
\hline Unemployed & 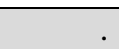 & . & 8 & 38 & 3 & 193 & 28 & 4 & 162 \\
\hline Manual Labour & 2 & 1 & 24 & 48 & 71 & 329 & 19 & 79 & 132 \\
\hline Spec. Manual Labour & $\cdot$ & . & 26 & 102 & 144 & 972 & 84 & 131 & 663 \\
\hline General High-Skilled & $x^{2}$ & . & 3 & 9 & 7 & 224 & 110 & 86 & 1318 \\
\hline Spec. High-Skilled & 1 & . & . & - & 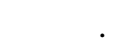 & 10 & 24 & 25 & 141 \\
\hline Administrative & & 2 & 1 & 5 & 5 & 35 & 10 & 13 & 282 \\
\hline Study & 2 & 2 & 163 & 12 & 8 & 224 & 73 & 22 & 229 \\
\hline Other & & & 17 & 31 & 7 & 239 & 37 & 25 & 325 \\
\hline Downshifters & • & • & 8 & 86 & 74 & 522 & 131 & 214 & 957 \\
\hline Non-Downshifters & 5 & 5 & 234 & 159 & 171 & 1704 & 254 & 171 & 2295 \\
\hline
\end{tabular}

Although the baseline definition is widely used in the literature, we have reasons to believe that its core assumption - namely that education is a good signal of an individual's labour market skills - may be questioned in the context of many transition economies, such as Ukraine. Aside from the fact that education may not proxy well unobservable skills (see for example Heckman and Rubinstein, 2000) there is also evidence that in transition countries, the inherited system of education has not been well adapted to the needs of a market economy. This implies that the signal from education to skills has become less robust than might normally be the case. This suggests that using the conventional measure may potentially be misleading.

A novel feature of our survey was the collection of information on migrants' labour market status ex ante and ex post migration. This information allows us to relate a migrant's occupational choice abroad to their prior occupational choice at home by including an additional set of covariates. Table 6 relates whether a person downshifted abroad to whether they had downshifted at home.

It is clear that 169 out of 288 downshifters (or slightly less than 60\%) had not been well matched in Ukraine prior to migration, implying that downshifting abroad may not be understood simply in terms of their inability to find appropriate work or other related explanations.

With this in mind, we provide an alternative definition of downshifting. A downshifter has to meet either of the following criteria:

- Involuntarily unemployed abroad if employed in Ukraine;

- Employed in an occupation abroad that is below the pre-migration level.

\footnotetext{
${ }^{10}$ Shaded area contains downshifters according to our baseline definition. Skills levels are defined as follows: Low= primary and basic secondary education; Medium= complete secondary and vocational; High= Tertiary. A dot indicates zero value.
} 


\section{Table 6: Tabulation of downshifters abroad vs downshifters in Ukraine}

\begin{tabular}{rc|rr|r} 
& & \multicolumn{3}{|c}{ Downshift Abroad } \\
& & No & Yes & Total \\
\hline & No & 299 & 119 & $\mathbf{4 1 8}$ \\
\hline & Yes & 48 & 169 & $\mathbf{2 1 7}$ \\
\cline { 2 - 5 } & Total & $\mathbf{3 4 7}$ & $\mathbf{2 8 8}$ & $\mathbf{6 3 5}$
\end{tabular}

When applying this filter, instead of the total of 288 people classified as downshifters in the standard or baseline case, the number shrinks to 116 or less than $20 \%$ of the 635 migrants in our dataset. This suggests that the baseline estimate with its underlying and strong assumptions concerning the relation between education and skills may be inappropriate in this context.

Table 7: Downshifters: baseline definition vs alternative definition

\begin{tabular}{rc|rr|r} 
& & \multicolumn{3}{|c}{ Downshift Baseline } \\
& No & Yes & Total \\
\hline & No & 342 & 177 & $\mathbf{5 1 9}$ \\
\hline & Yes & 5 & 111 & $\mathbf{1 1 6}$ \\
\cline { 3 - 5 } & Total & $\mathbf{3 4 7}$ & $\mathbf{2 8 8}$ & $\mathbf{6 3 5}$
\end{tabular}

We now proceed to formalize a simple model and then estimate it using data collected in the survey. In so doing, we will work with both the baseline and alternative definitions of downshifting.

\section{Model and Identification}

Our framework is based on a random utility model. We assume that each individual has two distinct decisions to make - to migrate or not and then whether to downshift or not, provided the first one is positive. That is, the decisions are made sequentially as indicated in the decision tree below (Figure 1). 


\section{Figure 1: Decision tree}

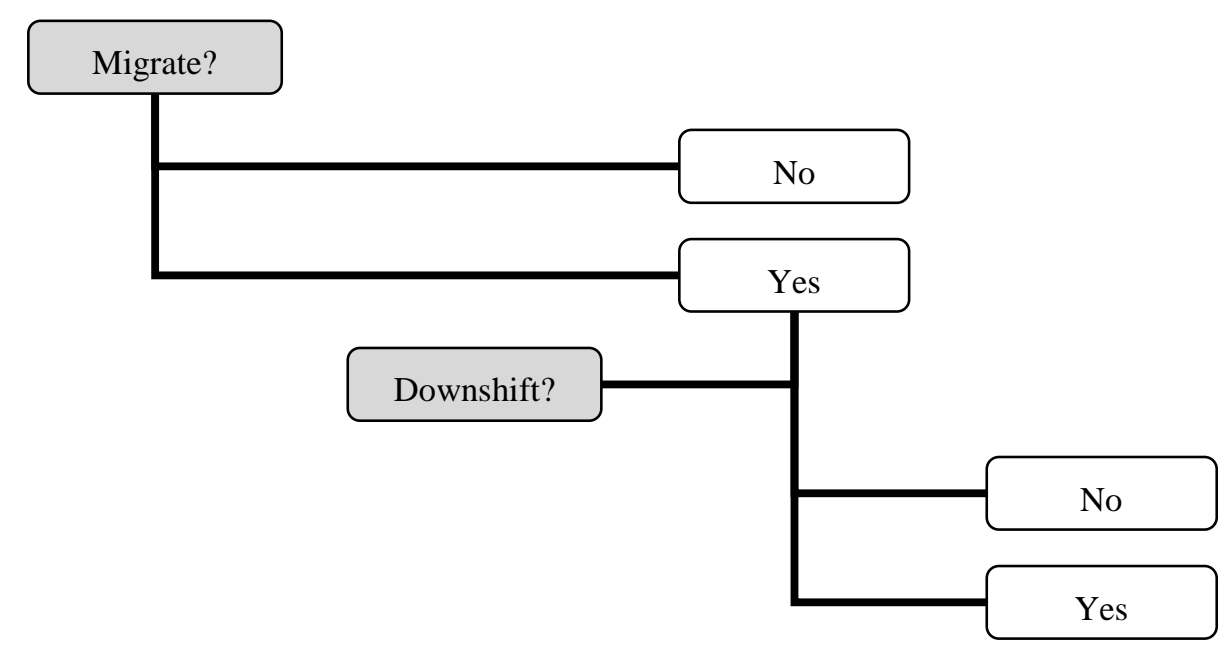

The utility levels associated with each of the decisions have both individual specific and random components that can be represented by the following two equations:

$$
\begin{aligned}
& y_{1}^{*}=X_{1}^{\prime} \beta_{1}+\varepsilon_{1}, \\
& y_{2}^{*}=X_{2}^{\prime} \beta_{2}+\varepsilon_{2} .
\end{aligned}
$$

Here, $y_{1}^{*}$ is the individual utility associated with the decision to migrate, $y_{2}^{*}$ is the individual utility associated with the decision to downshift, $X_{1}^{\prime}$ and $X_{2}^{\prime}$ are vectors of individual characteristics, $\varepsilon_{1}$ and $\varepsilon_{2}$ are the respective random components modeled as a bivariate normal distribution with zero means and correlation $\rho$, that is, $\left(\varepsilon_{1}, \varepsilon_{2}\right) \sim N\left(0,0, \varepsilon_{1}^{2}, \varepsilon_{2}^{2}, \rho\right)$.

There are two technical issues that have to be worked around in order to estimate, $\beta_{1}$ and $\beta_{2}$. First, instead of the actual utility levels $y_{1}^{*}$ and $y_{2}^{*}$, we can only observe the final choices made by an individual:

$$
y_{1}= \begin{cases}1 & \text { iff } y_{1}^{*}>0 \\ 0 & \text { iff } y_{1}^{*} \leq 0\end{cases}
$$

and:

$$
y_{2}= \begin{cases}1 & \text { iff } y_{2}^{*}>0 \\ 0 & \text { iff } y_{2}^{*} \leq 0 \\ - & \text { iff } y_{1}^{*} \leq 0\end{cases}
$$

Second, there are three types of observations, not four, available in the sample. While we can always observe $y_{1}, y_{2}$ can only be observed for those individuals for whom $y_{1}=1$. And since we cannot rule out the possibility of the two equations being interrelated (i.e. $\rho \neq 0$ ), they 
cannot be estimated using a standard probit. Effectively, we have a potential sample selection issue in the second equation and will have to use a natural extension of the celebrated Heckman (1979) sample selection model to the binary outcome variable case. The probit model with sample selection (see de Ven and Praag, 1981), sometimes referred to as "Heckprob", implies that three types of observations in our sample are to be observed with the following probabilities:

$$
\begin{array}{ll}
y_{1}=0 & P\left(y_{1}=0\right)=\Phi\left(-X_{1}^{\prime} \beta_{1}\right) \\
y_{1}=1, y_{2}=0 & P\left(y_{1}=1, y_{2}=0\right)=\Phi\left(X_{1}^{\prime} \beta_{1}\right)-\Xi\left(X_{1}^{\prime} \beta_{1}, X_{2}^{\prime} \beta_{2}, \rho\right) \\
y_{1}=1, y_{2}=1 & P\left(y_{1}=1, y_{2}=1\right)=\Xi\left(X_{1}^{\prime} \beta_{1}, X_{2}^{\prime} \beta_{2}, \rho\right) .
\end{array}
$$

where, $\Phi($.$) is the normal cdf, and \Xi($.$) is the bivariate normal cdf. Using the above$ probabilities and individual weights, $w_{i}$, it is then possible to construct the log-likelihood function:

$$
\begin{aligned}
\ln L= & \sum_{i=1}^{N} w_{i}\left\{\left(1-y_{i 1}\right) \ln \Phi\left(-X_{1}^{\prime} \beta_{1}\right)+\right. \\
& +y_{i 1}\left(1-y_{i 2}\right) \ln \left[\Phi\left(X_{1}^{\prime} \beta_{1}\right)-\Xi\left(X_{1}^{\prime} \beta_{1}, X_{2}^{\prime} \beta_{2}, \rho\right)\right]+ \\
& \left.+y_{i 1} y_{i 2} \ln \Xi\left(X_{1}^{\prime} \beta_{1}, X_{2}^{\prime} \beta_{2}, \rho\right)\right\} .
\end{aligned}
$$

The covariates used in the selection equation (1) and the outcome equation (2) are defined in Appendix Table 2. As the identifying restrictions in the selection equation we use two blocks of covariates: a migrant's education and the presence of another migrant in the family. We expect that a migrant's education level could affect the probability of emigration because of factors such as skill selection immigration policies. Skilled individuals tend to be mobile (for a host of reasons) and policy regimes - particularly in the advanced economies - tend to be far more welcoming to skilled, as opposed to unskilled migrants. The presence of a migrant in a household captures possible network effects that have been found to be important. This effect decreases information acquisition, migration and assimilation costs for a potential migrant that comes from a household that has already been exposed to some migration experience (Beine et al., 2011).

\section{Estimation Results}

The estimation results of the log-likelihood function in (3) are presented in Tables 8 and 9. The estimates of the selection equation converge for both definitions although the estimates of the downshift equation provide slightly different but consistent results.

Regarding the decision to migrate, an average migrant is a married male most likely to originate from the West or South of Ukraine and who typically comes from the middle (vocational training) or upper (Master's degree and above) parts of the education distribution. Regarding age, there is some concavity as the emigration probability increases to around 35 years and then declines. Household income levels add to the migration probability in a non-linear manner. Being from an average and above-average income family adds $5.7 \%$ and $14.6 \%$ to the migration probability respectively. City size, as a proxy for average income, also reveals a 
concave shape on the probability to migrate - respondents from both small and large cities are less likely to be migrants. It can be conjectured that this effect may arise through different channels - in small towns people have fewer opportunities and lower resources/information to cover migration costs. By contrast, in large cities relatively good work opportunities may deter migration.

The assumption of the exogeneity of income to the migration / downshift decision needs to be briefly discussed. Reverse causality may be an issue here. Migrants emigrate because of the income differential, therefore migrants are likely to be wealthier, which affects the probability to emigrate and / or downshift. However, in the context of our study, we address the issue in two ways. First, we include family income, not that of the migrant. Family income is affected by emigration mainly through the remittance channel. It appears that those families that do receive remittances use them to finance consumption, rarely investment. Second, we did not find evidence of migrants employed in highly paying occupations. 
Table 8: Selection equation estimates $\{* *-1 \%, * *-5 \%, *-10 \%$ significance levels respectively. Standard errors are clustered by family id\}

\begin{tabular}{|c|c|c|c|c|c|c|c|c|c|c|c|c|}
\hline \multirow{3}{*}{$\begin{array}{l}\text { Variable } \\
\text { reg west }\end{array}$} & \multicolumn{6}{|c|}{ Baseline Definition } & \multicolumn{6}{|c|}{ Alternative Definition } \\
\hline & \multicolumn{2}{|c|}{ Estimate } & S.E. & \multicolumn{2}{|c|}{$\mathrm{dy} / \mathrm{dx}$} & \multirow{2}{*}{$\frac{\text { S.E. }}{0.019}$} & \multicolumn{2}{|c|}{ Estimate } & \multirow{2}{*}{$\begin{array}{l}\text { S.E. } \\
0.085\end{array}$} & \multicolumn{2}{|c|}{$\mathrm{dy} / \mathrm{dx}$} & \multirow{2}{*}{$\frac{\text { S.E. }}{0.020}$} \\
\hline & 0.345 & $* * *$ & 0.085 & 0.080 & $* * *$ & & 0.330 & $* * *$ & & 0.077 & $* * *$ & \\
\hline reg_east & 0.160 & $*$ & 0.085 & 0.037 & $*$ & 0.020 & 0.154 & $*$ & 0.085 & 0.036 & $*$ & 0.020 \\
\hline reg_south & 0.396 & $* * *$ & 0.082 & 0.092 & $* * *$ & 0.019 & 0.371 & $* * *$ & 0.082 & 0.087 & $* * *$ & 0.019 \\
\hline town_100 & -0.268 & $* * *$ & 0.092 & -0.062 & $* * *$ & 0.022 & -0.274 & $* * *$ & 0.091 & -0.064 & $* * *$ & 0.022 \\
\hline town_200 & 0.059 & & 0.074 & 0.014 & & 0.017 & 0.056 & & 0.075 & 0.013 & & 0.017 \\
\hline town_500 & 0.017 & & 0.114 & 0.004 & & 0.026 & 0.024 & & 0.115 & 0.006 & & 0.027 \\
\hline town_1000 & -0.130 & $*$ & 0.070 & -0.030 & $*$ & 0.016 & -0.146 & $* *$ & 0.071 & -0.034 & $* *$ & 0.017 \\
\hline male & 0.465 & $* * *$ & 0.077 & 0.108 & $* * *$ & 0.019 & 0.488 & $* * *$ & 0.080 & 0.114 & $* * *$ & 0.020 \\
\hline age & 0.142 & $* * *$ & 0.022 & 0.033 & $* * *$ & 0.005 & 0.147 & $* * *$ & 0.024 & 0.034 & $* * *$ & 0.006 \\
\hline age2 & -0.002 & $* * *$ & 0.000 & 0.000 & $* * *$ & 0.000 & -0.002 & $* * *$ & 0.000 & 0.000 & $* * *$ & 0.000 \\
\hline family_above & 0.631 & $* * *$ & 0.110 & 0.146 & $* * *$ & 0.026 & 0.638 & $* * *$ & 0.113 & 0.149 & $* * *$ & 0.027 \\
\hline family_avg & 0.247 & $* * *$ & 0.068 & 0.057 & $* * *$ & 0.016 & 0.245 & $* * *$ & 0.069 & 0.057 & $* * *$ & 0.016 \\
\hline educ_secondary & 0.199 & & 0.192 & 0.046 & & 0.045 & 0.330 & & 0.222 & 0.077 & & 0.052 \\
\hline educ_vocational & 0.525 & $* * *$ & 0.197 & 0.122 & $* * *$ & 0.047 & 0.674 & $* * *$ & 0.214 & 0.157 & $* * *$ & 0.051 \\
\hline educ_bachelor & 0.235 & & 0.201 & 0.054 & & 0.047 & 0.535 & $* *$ & 0.221 & 0.125 & $* *$ & 0.052 \\
\hline educ_master & 0.381 & $*$ & 0.201 & 0.088 & $*$ & 0.047 & 0.588 & $* *$ & 0.229 & 0.137 & $* *$ & 0.054 \\
\hline educ_phd & 0.994 & $* * *$ & 0.338 & 0.230 & $* * *$ & 0.079 & 1.183 & $* * *$ & 0.359 & 0.276 & $* * *$ & 0.085 \\
\hline single & -0.254 & $* * *$ & 0.085 & -0.059 & $* * *$ & 0.020 & -0.260 & $* * *$ & 0.087 & -0.061 & $* * *$ & 0.020 \\
\hline hh_head & -0.544 & $* * *$ & 0.099 & -0.126 & $* * *$ & 0.023 & -0.532 & $* * *$ & 0.102 & -0.124 & $* * *$ & 0.024 \\
\hline hh_spouse & -0.662 & $* * *$ & 0.120 & -0.153 & $* * *$ & 0.028 & -0.651 & $* * *$ & 0.123 & -0.152 & $* * *$ & 0.029 \\
\hline hh_med & -0.059 & & 0.075 & -0.014 & & 0.017 & -0.069 & & 0.075 & -0.016 & & 0.018 \\
\hline hh_large & 0.006 & & 0.103 & 0.001 & & 0.024 & -0.007 & & 0.104 & -0.002 & & 0.024 \\
\hline unempl_y_ua & 0.393 & $* * *$ & 0.118 & 0.091 & $* * *$ & 0.028 & 0.488 & $* * *$ & 0.136 & 0.114 & $* * *$ & 0.032 \\
\hline unempl_o_ua & 0.440 & $* * *$ & 0.090 & 0.102 & $* * *$ & 0.021 & 0.494 & $* * *$ & 0.099 & 0.115 & $* * *$ & 0.023 \\
\hline migr_fam & 0.410 & $* * *$ & 0.110 & 0.095 & $* * *$ & 0.026 & 0.475 & $* * *$ & 0.121 & 0.111 & $* * *$ & 0.029 \\
\hline cons & -4.436 & $* * *$ & 0.486 & & & & -4.758 & $* * *$ & 0.515 & & & \\
\hline & log pseuc & olike & od: -20 & 18 & & & log pseu & olike & od: -20 & .270 & & \\
\hline & Cens & & & & & & & & & & & \\
\hline
\end{tabular}


Table 9: Downshift equation estimates $\{* * *-1 \%, * *-5 \%, *-10 \%$ significance levels. Standard errors are clustered by family id $\}$

\begin{tabular}{|c|c|c|c|c|c|c|c|c|c|c|c|c|}
\hline \multirow{3}{*}{$\begin{array}{l}\text { Variable } \\
\text { shift_ua }\end{array}$} & \multicolumn{6}{|c|}{ Baseline Definition } & \multicolumn{6}{|c|}{ Alternative Definition } \\
\hline & \multicolumn{2}{|c|}{ Estimate } & S.E. & \multicolumn{2}{|c|}{$\mathrm{dy} / \mathrm{dx}$} & \multirow{2}{*}{$\begin{array}{l}\text { S.E. } \\
0.019\end{array}$} & \multicolumn{2}{|c|}{ Estimate } & \multirow[t]{2}{*}{ S.E. } & \multicolumn{2}{|c|}{$\mathrm{dy} / \mathrm{dx}$} & \multirow[t]{2}{*}{ S.E. } \\
\hline & 0.671 & $* * *$ & 0.107 & 0.092 & $* * *$ & & & & & & & \\
\hline Reg_west & 0.212 & & 0.138 & 0.029 & & 0.019 & 0.269 & & 0.203 & 0.020 & & 0.015 \\
\hline Reg_east & 0.117 & & 0.135 & 0.016 & & 0.019 & 0.228 & & 0.188 & 0.017 & & 0.015 \\
\hline Reg_south & 0.153 & & 0.132 & 0.021 & & 0.018 & 0.458 & $* *$ & 0.185 & 0.033 & $* *$ & 0.016 \\
\hline town_100 & -0.137 & & 0.155 & -0.019 & & 0.021 & -0.295 & & 0.221 & -0.022 & & 0.018 \\
\hline town_200 & -0.030 & & 0.115 & -0.004 & & 0.016 & -0.181 & & 0.157 & -0.013 & & 0.013 \\
\hline town_500 & 0.261 & & 0.170 & 0.036 & & 0.023 & 0.078 & & 0.243 & 0.006 & & 0.017 \\
\hline town_1000 & -0.305 & $* * *$ & 0.114 & -0.042 & $* *$ & 0.017 & -0.387 & $* *$ & 0.160 & -0.028 & $*$ & 0.016 \\
\hline male & 0.285 & $* *$ & 0.120 & 0.039 & $* *$ & 0.016 & 0.257 & & 0.160 & 0.019 & & 0.011 \\
\hline Age & 0.167 & $* * *$ & 0.029 & 0.023 & $* * *$ & 0.004 & 0.171 & $* * *$ & 0.049 & 0.012 & $* * *$ & 0.004 \\
\hline Age2 & -0.002 & $* * *$ & 0.000 & 0.000 & $* * *$ & 0.000 & -0.002 & $* * *$ & 0.001 & 0.000 & $* * *$ & 0.000 \\
\hline family_above & 0.429 & $* *$ & 0.192 & 0.059 & $* *$ & 0.026 & 0.196 & & 0.308 & 0.014 & & 0.023 \\
\hline family_avg & 0.337 & $* * *$ & 0.110 & 0.046 & $* * *$ & 0.016 & 0.208 & & 0.156 & 0.015 & & 0.012 \\
\hline single & -0.091 & & 0.116 & -0.012 & & 0.016 & -0.179 & & 0.155 & -0.013 & & 0.011 \\
\hline hh_head & -0.411 & $* * *$ & 0.122 & -0.056 & $* * *$ & 0.017 & -0.368 & $* *$ & 0.163 & -0.027 & $* *$ & 0.013 \\
\hline hh_spouse & -0.317 & $* *$ & 0.155 & -0.044 & $* *$ & 0.021 & -0.397 & $* *$ & 0.226 & -0.029 & $*$ & 0.017 \\
\hline hh_med & -0.129 & & 0.110 & -0.018 & & 0.015 & -0.240 & & 0.150 & -0.018 & & 0.012 \\
\hline hh_large & 0.057 & & 0.147 & 0.008 & & 0.020 & -0.234 & & 0.201 & -0.017 & & 0.016 \\
\hline times_traveled & 0.015 & & 0.021 & 0.002 & & 0.003 & 0.022 & & 0.034 & 0.002 & & 0.003 \\
\hline russia & -0.043 & & 0.125 & -0.006 & & 0.017 & 0.282 & & 0.233 & 0.021 & & 0.019 \\
\hline europe & 0.098 & & 0.115 & 0.013 & & 0.016 & 0.405 & $*$ & 0.218 & 0.030 & & 0.019 \\
\hline Usa & 0.204 & & 0.212 & 0.028 & & 0.030 & 0.323 & & 0.331 & 0.024 & & 0.025 \\
\hline Stay_duration & 0.000 & & 0.001 & 0.000 & & 0.000 & -0.002 & $* *$ & 0.001 & 0.000 & $*$ & 0.000 \\
\hline status_work & -0.047 & & 0.087 & -0.006 & & 0.012 & -0.055 & & 0.170 & -0.004 & & 0.013 \\
\hline status_residence & -0.201 & & 0.145 & -0.028 & & 0.020 & -0.045 & & 0.236 & -0.003 & & 0.017 \\
\hline reason_pay & 0.217 & $* *$ & 0.104 & 0.030 & $*$ & 0.015 & 0.143 & & 0.154 & 0.010 & & 0.012 \\
\hline language & -0.144 & & 0.104 & -0.020 & & 0.015 & -0.306 & $*$ & 0.163 & -0.022 & & 0.014 \\
\hline migraid_received & -0.008 & & 0.077 & -0.001 & & 0.011 & 0.011 & & 0.128 & 0.001 & & 0.009 \\
\hline sponsor_nat_ua & 0.004 & & 0.157 & 0.001 & & 0.022 & -0.619 & $* *$ & 0.288 & -0.045 & $*$ & 0.025 \\
\hline sponsor_nat_cy & 0.021 & & 0.085 & 0.003 & & 0.012 & 0.125 & & 0.157 & 0.009 & & 0.012 \\
\hline cons & -5.033 & $* * *$ & 0.621 & & & & -5.407 & $* * *$ & 1.025 & & & \\
\hline Rho & 2.182 & $* * *$ & 0.515 & & & & 1.098 & $* * *$ & 0.419 & & & \\
\hline
\end{tabular}


As far as the estimates of the determinants of downshifting are concerned, we have results from both the baseline and alternative definitions. For both definitions it is true, though at varying significance levels, that a downshifter is unlikely to be a household head or spouse of the head. Downshifters also do not come from large cities (with populations $>1$ million). The former effect holds because the household head or spouse are more likely to be selective in their occupation and migration decisions. The large city effect comes in through the budget constraint. As in the selection equation, there is a concave shape with respect to age - the probability of downshifting increases with age up to around 42 years and then steadily declines.

For a typical baseline downshifter - mostly male - the main reason for migration is higher wage and better employment opportunities. The aim of higher earnings means that migrants may accept lower level occupations than their educational attainments might suggest. Migrants' details about employment prior to emigration seem to account for much of variation in the baseline downshifting. Migrants' prior position in the labour market proves a decent predictor of their future position. Thus, if a respondent was a baseline downshifter in Ukraine, he is 9.2\% more likely to be a downshifter abroad.

The probability of being a downshifter when using the alternative definition decreases with the duration of stay in a foreign country and knowledge of the local language or English. Those employed by a Ukrainian employer are also less likely to be alternative downshifters. Alternative downshifters are both female and male and are likely to come from the south of Ukraine. For somebody who speaks the language of the host country at an intermediate level or above, the probability of downshifting decreases by $2.2 \%$. Knowledge of the language, as well as the duration of stay might, of course, correlate with unobserved ability whereby more able migrants may learn the local language and stay longer. Migrants westwards to the EU states are - by a small margin, 3\% - more likely to be downshifters.

\section{Conclusions}

Our paper has focused on patterns of self-selection and labour market outcomes among Ukrainian migrants. It confirms significant selection on gender and education - migrants in particular are more likely to be males from the higher end of the education distribution. However, when it comes to the labour market outcomes of migrants in the receiving country, we find that there is a pattern of occupational downshifting. Indeed, over $45 \%$ of the migrants have a level of education that by far exceeds the job requirements. This might be attributed to the migrants having a disadvantageous position in local labour markets - whether through discrimination or informational shortcomings - or it might be related to their 'true' attributes which are not necessarily well captured by an education level. To address this, we look at labour market outcomes at two points in time - before and after emigration. We find that a person who had previously downshifted in Ukraine was over 9\% more likely to be a downshifter abroad. This suggests that education is indeed a noisy signal of individual unobserved ability and an alternative measure may be called for. We set up a simple model that focuses on the migration and downshifting decisions sequentially and estimate it using our survey data. When using the alternative measure of downshifting, we find that the duration of stay, knowledge of the local language (or English) or having an employer that is Ukrainian is less likely to be associated with downshifting. The title of our paper asked whether Ukrainian migration has been mainly about skilled (brain) or unskilled (brawn) migration. The answer is qualified. For those migrants currently abroad, the picture is one where in terms of educational attainments a clear majority has some level of tertiary education. The profile appears biased towards skills. However, when looking at what Ukrainian migrants do when they migrate, a 
significant share work in occupations that appear to match poorly to their prior educational attainments. This suggests that that migration involves downshifting. But this picture is itself somewhat misleading as our analysis shows that a significant number of these downshifters had already downshifted at home prior to migrating. We consider that drawing strong conclusions about the efficiency of occupation-education matching may not be warranted. Rather, what may be a more promising avenue of enquiry - particularly from a policy perspective - is to consider why it is that the educational attainments of Ukrainians have such an attenuated link to labour market outcomes. The answer is likely to lie in the deficiencies of the current educational system and the limited adaptation that has been made to the needs of the labour market in a market economy whether at home or abroad. 


\section{References}

Adsera, A. and Chiswick, B. (2007). Are there gender and country of origin differences in immigrant labor market outcomes across European destinations? Journal of Population Economics, 20 (3), 495 - 526.

Ambrosini, J. and Peri, G. (2012). The determinants and the selection of Mexico - US migrants. The World Economy, 35 (2), 111 - 151.

Batista, C., Lacuesta, A. and Vicente, P. (2012). Testing the brain gain hypothesis: micro evidence from Cape Verde. Journal of Development Economics, 97 (1), 32 - 45.

Beine, M., Docquier, F. and Ozden, C. (2011). Diasporas. Journal of Development Economics, 95 (1), $30-41$.

Berman, E., Lang, K. and Siniver, E. (2003). Language-skill complementarity: returns to immigrant language acquisition. Labour Economics, 10 (3), 265 - 290.

Bhagwati, J. and Hamada, K. (1974). The brain drain, international integration of markets for professionals and unemployment: a theoretical analysis. Journal of Development Economics, 1 (1), $19-42$.

Borjas, B. (1987). Self-selection and the earnings of immigrants. American Economic Review, 77 (4), 531-553.

Chiquiar, D. and Hanson, G. (2005). International migration, self-selection, and the distribution of wages: evidence from Mexico and the United States. Journal of Political Economy, 113, 239 $-281$.

Co, K., Gang, I. and Yum, M.-S. (2000). Returns to returning. Journal of Population Economics, 13, 57 - 79.

Commander, S., Kangasniemi, M. and Winters, L. (2003). The brain drain: curse or boom? in R. Baldwin and L.A. Winters (editors), 'Challenges to Globalisation', NBER and University of Chicago..

Van de Ven, W. P. V. and Praag, B. M. V. (1981). The demand for deductibles in private health insurance: A probit model with sample selection. Journal of Econometrics, 17 (2), 229 - 252.

ETF (2008). The contribution of human resources development to migration policy in Ukraine. European Training Foundation country report: Ukraine.

Friedberg, R. (2000). You can't take it with you? Immigrant assimilation and the portability of human capital. Journal of Labour Economics, 18 (2), 221 - 251.

Gibson, J. and McKenzie, D. (2012). The economic consequences of brain drain of the best and brightest: microeconomics evidence from five countries. The Economic Journal, 122, 339 375.

Hanson, G. H. (2006). Illegal migration from Mexico to the United States. Journal of Economic Literature, 44 (4), 869 - 924.

Heckman, J. and Rubinstein, Y. (2000). The importance of noncognitive skills: Lessons from 
the GED testing program. American Economic Review, 91 (2), 145 - 149.

Heckman, J. J. (1979). Sample selection bias as a specification error. Econometrica, 47 (1), 153 $-161$.

Kostenko, W., Harris, M. and Zhao, X. (2012). Occupational transition and country-of- origin effects in the early stage occupational assimilation of immigrants: some evidence from Australia. Applied Economics, 44 (31), 4019 - 4035.

Libanova, E. M. (2009). External labor migration of the Ukrainian population (in Ukrainian). Kiev: Ukrainian Center for Social Reforms, Ukrainian Statistical Committee.

Mattoo, A., Neagu, I. C. and Ozden, C. (2008). Brain waste? Educated immigrants in the US labor market. Journal of Development Economics, 87, 255 - 269.

McKenzie, D. and Rapoport, H. (2010). Self-selection patterns in Mexico - U.S. migration: the role of migration networks. Review of Economics and Statistics, 92 (4), 811 - 821.

Moraga, J. F.-H. (2011). New evidence on emigrant selection. Review of Economics and Statistics, 93 (1), $72-96$.

Nicoli, M., Carazza, C. and Bank, W. (2010). The Market for Remittance Services in the Czech Republic: Outcomes of a Survey Among Migrants. World Bank, World Bank.

Osipian, A. L. (2012). Economics of corruption in doctoral education: The dissertations market. Economics of Education Review, 31 (1), 76 - 83.

Rooth, D.-O. and Saarela, J. (2007). Selection in migration and return migration: Evidence from micro data. Economic Letters, 94, 90 - 95.

Turner, T. (2010). The jobs immigrants do: issues of displacement and marginalisation in the Irish labour market. Work, Employment and Society, 24 (2), 318 - 336.

United Nations (2011). Trends in international migrant stock: migrants by age and sex. New York: United Nations. 


\section{Appendix}

Appendix Table 1: Migration rates and chosen destinations by region

\begin{tabular}{|c|c|c|c|c|c|}
\hline \multirow[b]{2}{*}{ ID } & \multirow[b]{2}{*}{ Region } & \multirow{2}{*}{$\begin{array}{l}\text { Migration } \\
\text { rate, \% }\end{array}$} & \multicolumn{3}{|c|}{ Chosen destination, \% } \\
\hline & & & Russia & EU27 & ROW \\
\hline 1 & Zhytomyr & 1.8 & 36.8 & 63.2 & 0.0 \\
\hline 2 & Zaporizhia & 3.4 & 20.1 & 35.4 & 44.5 \\
\hline 3 & Kharkiv & 5.2 & 62.7 & 26.9 & 10.4 \\
\hline 4 & Donetsk & 5.7 & 43.5 & 52.3 & 4.2 \\
\hline 5 & Vinnytsia & 5.9 & 0.0 & 39.7 & 60.3 \\
\hline 6 & Mykolaiv & 6.2 & 25.7 & 65.0 & 9.4 \\
\hline 7 & Kirovograd & 6.2 & 50.0 & 75.0 & 25.0 \\
\hline 8 & Krym & 6.7 & 47.4 & 25.9 & 26.7 \\
\hline 9 & Cherkasy & 6.9 & 40.2 & 48.9 & 10.9 \\
\hline 10 & Poltava & 7.1 & 51.7 & 48.3 & 0.0 \\
\hline 11 & Kyiv & 7.2 & 21.0 & 69.7 & 9.2 \\
\hline 12 & Khmelnytskyi & 8.2 & 29.0 & 71.0 & 0.0 \\
\hline 13 & Chernigiv & 9.5 & 27.3 & 43.6 & 29.1 \\
\hline 14 & Chernivtsi & 10.5 & 0.0 & 84.4 & 15.6 \\
\hline 15 & Lviv & 11.6 & 23.3 & 75.2 & 1.5 \\
\hline 16 & Zakarpattia & 11.8 & 38.2 & 55.7 & 6.1 \\
\hline 17 & Dnipropetrovsk & 11.8 & 68.4 & 20.4 & 11.2 \\
\hline 18 & Sumy & 14.3 & 75.1 & 13.0 & 11.9 \\
\hline 19 & Kherson & 14.5 & 35.3 & 56.0 & 8.7 \\
\hline 20 & Lugansk & 15.1 & 89.7 & 7.6 & 2.7 \\
\hline 21 & Ivano-Frankivsk & 17.1 & 19.7 & 65.6 & 14.8 \\
\hline 22 & Volyn & 17.9 & 49.7 & 50.3 & 0.0 \\
\hline 23 & Odesa & 22.3 & 25.6 & 29.4 & 45.0 \\
\hline 24 & Rivne & 37.6 & 44.4 & 52.2 & 3.4 \\
\hline 25 & Ternopil & 41.9 & 9.4 & 70.7 & 19.9 \\
\hline
\end{tabular}




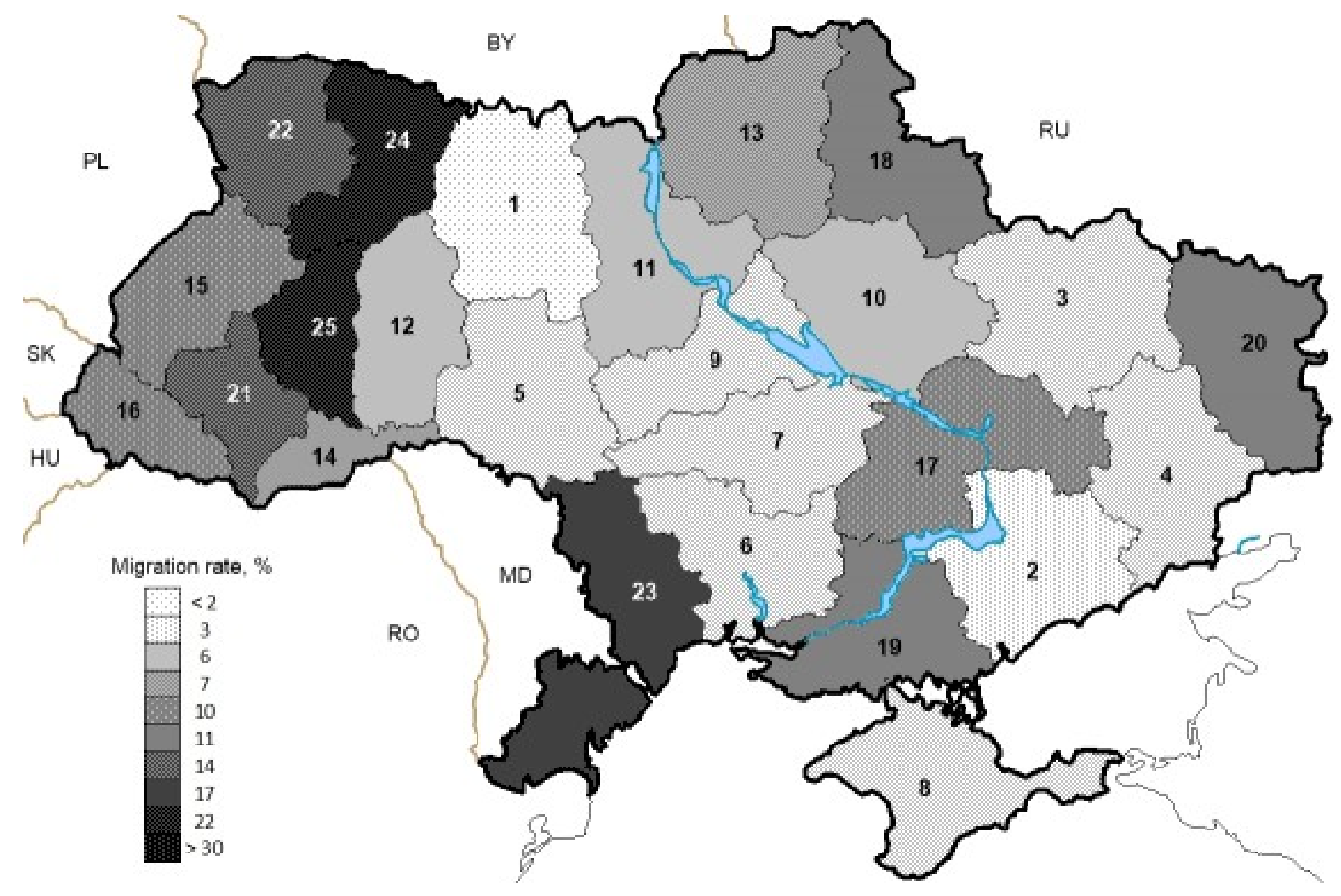

(a) Migration Rates, \%

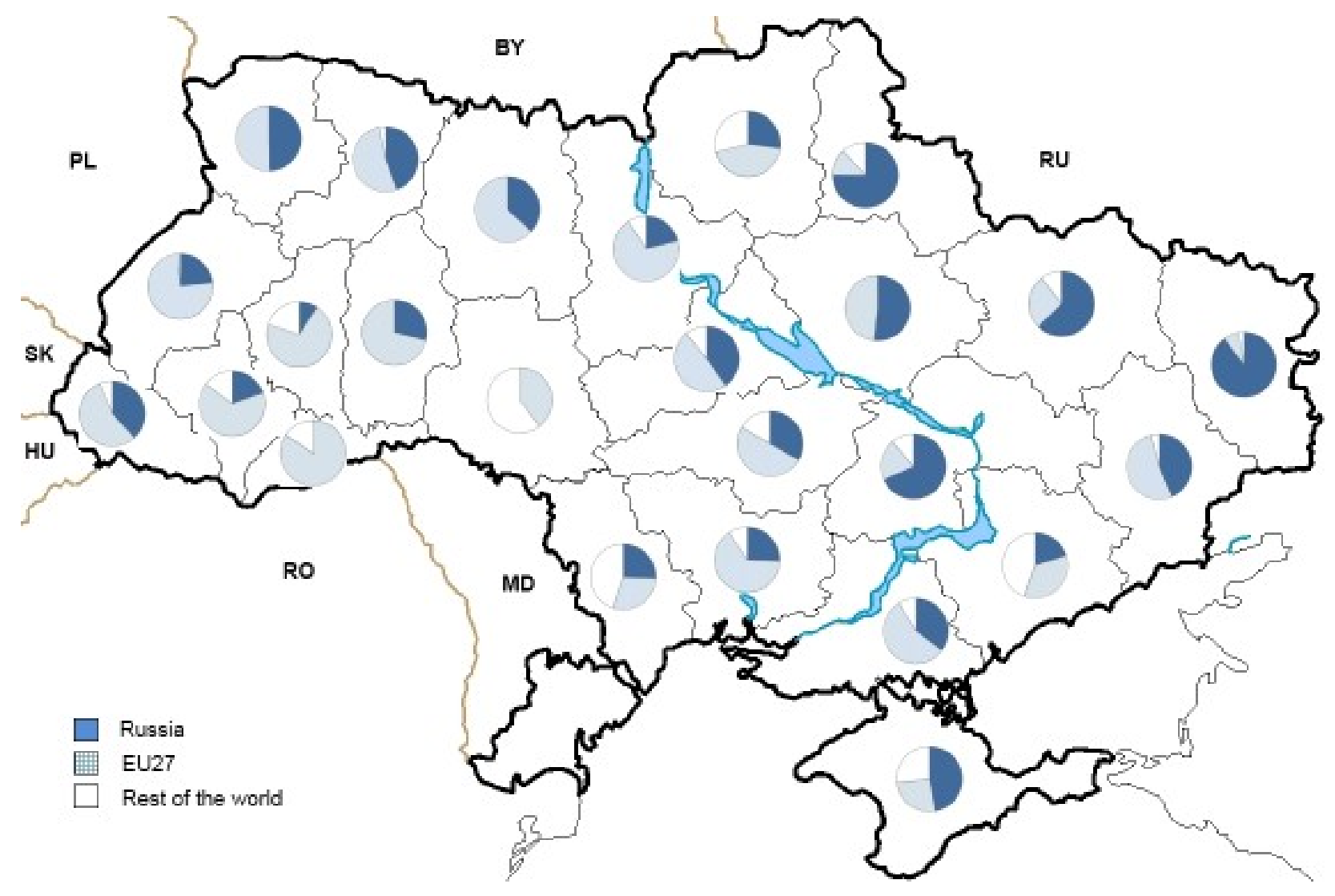

(b) Destination Choice 
Appendix Table 2: Variables dictionary

\begin{tabular}{|c|c|}
\hline Variable & Definition \\
\hline shift_ua & $=1$ if the respondent downshifted in Ukraine, and 0 otherwise. \\
\hline $\begin{array}{l}\text { reg_west } \\
\text { reg_east } \\
\text { reg_south }\end{array}$ & $\begin{array}{l}\text { Set of dummy variables, }=1 \text { if the respondent comes from the West, East } \\
\text { or South of Ukraine respectively, and } 0 \text { otherwise. The base region is the } \\
\text { North. }\end{array}$ \\
\hline $\begin{array}{l}\text { town_100 } \\
\text { town_200 } \\
\text { town_500 } \\
\text { town_1000 }\end{array}$ & $\begin{array}{l}\text { Set of dummy variables, }=1 \text { if the respondent lives in a settlement with } \\
\text { population } \\
{[100 \mathrm{k}-200 \mathrm{k}),[200 \mathrm{k}-500 \mathrm{k}),[500 \mathrm{k}-1000 \mathrm{k}) \text { and } \geq 1000 \mathrm{k} \text { people }} \\
\text { respectively. The base category is }[50 \mathrm{k}-100 \mathrm{k}) .\end{array}$ \\
\hline male & $=1$ if the respondent is male, and 0 otherwise. \\
\hline age & Respondent's age in years. \\
\hline $\begin{array}{l}\text { family_above } \\
\text { family_avg }\end{array}$ & $\begin{array}{l}\text { Set of dummy variables, = } 1 \text { if the respondent's self-reported income is } \\
\text { above average or average respectively. The base category is below } \\
\text { average. }\end{array}$ \\
\hline single & $=1$ if the respondent is single, divorced or widowed, and 0 otherwise. \\
\hline $\begin{array}{l}\text { hh_head } \\
\text { hh_spouse }\end{array}$ & $\begin{array}{l}\text { Set of dummy variables, = } 1 \text { if the respondent is the head of the } \\
\text { household or the spouse of the head respectively, and } 0 \text { otherwise. The } \\
\text { base category is all others (son, daughter etc). }\end{array}$ \\
\hline $\begin{array}{l}\text { hh_med } \\
\text { hh_large }\end{array}$ & $\begin{array}{l}=1 \text { if the respondent comes from a medium-sized ( } 3 \text { or } 4 \text { members) or } \\
\text { large ( } 5 \text { and above) household, and } 0 \text { otherwise. The base group is small } \\
\text { households with at most two members. }\end{array}$ \\
\hline times_traveled & $\begin{array}{l}\text { Number of times the respondent traveled to the same country for the } \\
\text { same purpose within the last three years (excluding occasional returns to } \\
\text { Ukraine). }\end{array}$ \\
\hline $\begin{array}{l}\text { russia } \\
\text { europe } \\
\text { usa }\end{array}$ & $\begin{array}{l}\text { Destination dummy variables, = } 1 \text { if the respondent went to a country of } \\
\text { the former Soviet Union (excluding the Baltic countries), EU } 27 \text { or North } \\
\text { America respectively, and } 0 \text { otherwise. The rest of the world is the base. }\end{array}$ \\
\hline stay_duration & Duration of stay (in years) in the destination country. \\
\hline $\begin{array}{l}\text { staus_work } \\
\text { status_residence }\end{array}$ & $\begin{array}{l}=1 \text { if the respondent has a work permit or permanent residency } \\
\text { respectively, and } 0 \text { otherwise. The base is all other categories. }\end{array}$ \\
\hline reason_pay & $\begin{array}{l}=1 \text { if the respondent's primary reason for migration was higher wage or } \\
\text { better employment opportunities, and } 0 \text { otherwise. }\end{array}$ \\
\hline language & $\begin{array}{l}=1 \text { if the respondent speaks the language of the destination country or } \\
\text { English on the level intermediate or above. }\end{array}$ \\
\hline
\end{tabular}




\begin{tabular}{|c|c|}
\hline migraid_received & $\begin{array}{l}=1 \text { if the respondent received any help to emigrate from friends / } \\
\text { relatives or co-workers in Ukraine, and } 0 \text { otherwise. }\end{array}$ \\
\hline $\begin{array}{l}\text { sponsor_nat_ua } \\
\text { sponsor_nat_cy }\end{array}$ & $\begin{array}{l}\text { Set of dummy variable, = } 1 \text { if the nationality of the respondent's } \\
\text { employer / sponsor is Ukrainian or that of the destination country } \\
\text { respectively, and } 0 \text { otherwise. The base is all other nationalities. }\end{array}$ \\
\hline $\begin{array}{l}\text { educ_secondary } \\
\text { educ_vocational } \\
\text { educ_bachelor } \\
\text { educ_master } \\
\text { educ_phd }\end{array}$ & $\begin{array}{l}\text { Set of education dummy variables, = } 1 \text { if the respondent has completed a } \\
\text { respective level of education: secondary, vocational, Bachelor's, Master's } \\
\text { or PhD, and } 0 \text { otherwise. The elementary level of education is taken for } \\
\text { the base. }\end{array}$ \\
\hline $\begin{array}{l}\text { unempl_y_ua } \\
\text { unempl_o_ua }\end{array}$ & $\begin{array}{l}\text { Set of dummy variables, }=1 \text { if the respondent is unemployed and aged } \\
{[15-30] \text { or }(30-59] \text { respectively, and } 0 \text { otherwise. }}\end{array}$ \\
\hline migr_fam & $=1$ if the family has a migrant (besides the current one), and 0 otherwise. \\
\hline
\end{tabular}

